\title{
Application of High-Resolution C-Arm CT Combined with Streak Metal Artifact Removal Technology for the Stent-Assisted Embolization of Intracranial Aneurysms
}

\author{
(D) T.-F. Li, (D). Ma, (D)X.-W. Han, (DP.-J. Fu, (DR.-N. Niu, (DW.-Z. Luo, and (D).-Z. Ren
}

\begin{abstract}
BACKGROUND AND PURPOSE: Metal artifacts from coils and stents limit the level of detail in C-arm CT images of stent attachment and coiling attenuation in the aneurysm neck. We evaluated the utility of high-resolution C-arm CT combined with streak metal artifact removal technology for stent-assisted embolization of intracranial aneurysms.
\end{abstract}

MATERIALS AND METHODS: From October 2017 to July 2018, the First Affiliated Hospital of Zhengzhou University treated 107 patients with intracranial aneurysms (118 aneurysms in total) with stent-assisted embolization. Conventional C-arm CT and high-resolution C-arm CT scanning of the stented area were performed during and after treatment. 3D images were reconstructed with and without streak metal artifact removal techniques. Subsequently, the image quality was compared. The reconstructed images indicated the stent deployment degree and packing density. Follow-up assessments included clinical and angiographic outcomes and complications.

RESULTS: In total, 118 aneurysms were successfully embolized using 118 stents. Image quality was significantly higher $(P<.05)$ with high-resolution C-arm CT combined with streak metal artifact removal reconstruction. Streak metal artifact removal reconstruction and 2D angiography at working angles showed incomplete deployment of 6 stents and incomplete aneurysm embolization of 15 patients, which were subsequently resolved. One case of hemorrhage was noted postoperatively. Follow-up of 93 patients at 6-13 months indicated 3 cases of aneurysm recurrence.

CONCLUSIONS: High-resolution C-arm CT combined with the streak metal artifact removal technique effectively reduced metal artifacts from stents and coils during aneurysm embolization. This method can help physicians determine the extent of stent deployment and the packing density of coils and thus potentially reduce complications and aneurysm recurrence.

ABBREVIATIONS: ISAT = International Subarachnoid Aneurysm Trial; MAR = metal artifact removal; MRRC = modified Raymond-Roy occlusion classification; SMART $=$ streak metal artifact reduction technology

S tent-assisted embolization is an important treatment method for wide-neck intracranial aneurysms, and its use is becoming more widespread. ${ }^{1-3}$ The successful embolization of intracranial aneurysms depends on the surgeon's understanding of intracranial blood vessel anatomy and the relationship among target blood vessels, interventional devices (stents and coils),

Received April 23, 2019; accepted after revision July 16

From the Departments of Interventional Radiology (T.-F.L., J.M., X.-W.H., P.-J.F.,

J.-Z.R.), Neurology (R.-N.N.), and Neurosurgery (W.-Z.L.), The First Affiliated Hospital

of Zhengzhou University, Zhengzhou, China; and Interventional Institute of

Zhengzhou University (T.-F.L., J.M., X.-W.H., P.-J.F., J.-Z.R), Zhengzhou, China.

T.-F. Li and J. Ma contributed equally to this work.

This work was supported by a grant from the National Natural Science Foundation of China (No. 81801806).

Please address correspondence to X.-W. Han, MD, No. 1 Jianshe Road, Zhengzhou City, Henan Province, China; e-mail: xinwei_han@163.com

- Indicates open access to non-subscribers at www.ajnr.org

http://dx.doi.org/10.3174/ajnr.A6190 and the surrounding tissues. The introduction of C-arm CT has helped resolve several problems associated with invisible structures during interventions. DynaCT Micro (Siemens, Erlangen, Germany) is a new generation of high-resolution C-arm CT developed by Siemens in 2016. Compared with traditional Carm CT (DynaCT; Siemens), its local spatial resolution is higher. Moreover, in combination with the metal artifact removal (MAR) technique, this new technique improves the visibility of stents. ${ }^{4}$ In October 2016, Zhengzhou University First Affiliated Hospital introduced China's first flat panel detector DSA system (Artis Zeego; Siemens) with DynaCT Micro function and used it to treat patients with aneurysms. Image reconstruction in those cases used the latest generation of MAR technology (streak metal artifact reduction technology [SMART]; Siemens). In an in vitro aneurysm model, we observed that this new technique significantly improved the postprocessing quality of images of stents and coils, such as 


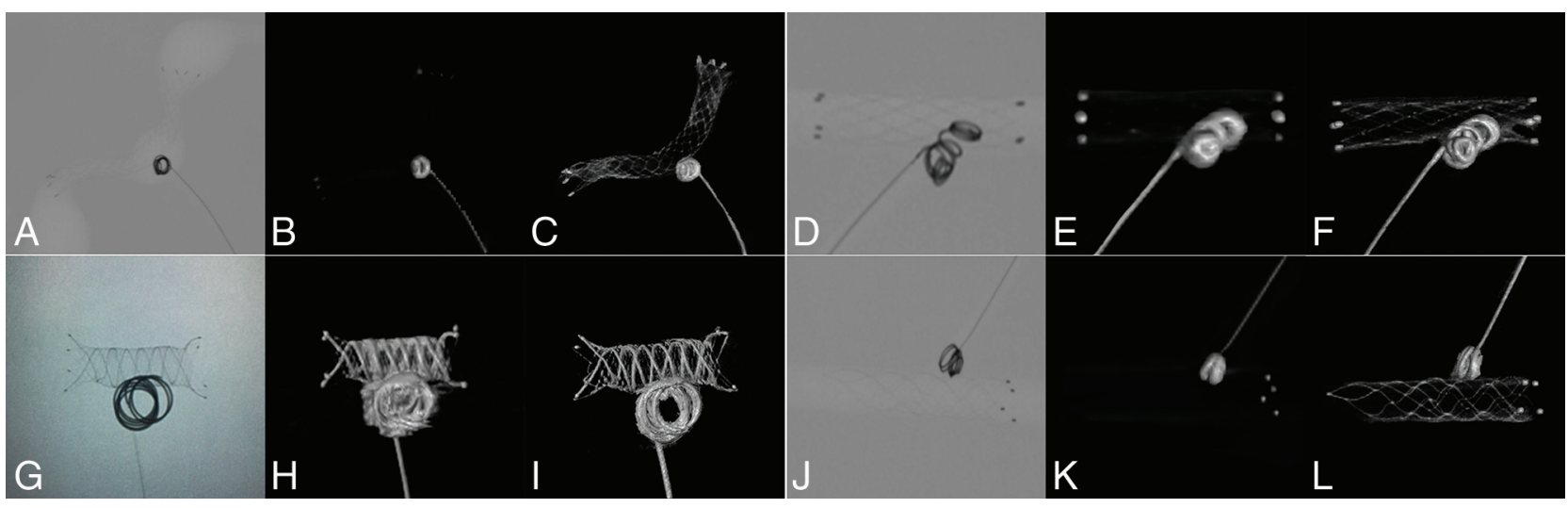

FIG 1. Different types of stents and coils in fluoroscopy, DynaCT, and DynaCT Micro combined with SMART image. A-C, Enterprise stent. $D-F$, Neuroform EZ stent. G-I, LVIS stent. J-L, Solitarie AB stent.

stent skeleton development and wire and coil metal artifact reduction (Fig 1). However, research on the use of this technique in aneurysms remains scarce. In the present study, we analyzed the reconstruction images of conventional C-arm CT (DynaCT) and high-resolution C-arm CT (DynaCT Micro) combined with SMART following the stent-assisted embolization of 118 intracranial aneurysms in 107 patients from October 2017 to July 2018 in the eastern district of our hospital. We assessed image quality, imaging characteristics, utility for guiding intravascular treatment, and the clinical value of high-resolution C-arm CT (DynaCT Micro) combined with SMART for the stent-assisted embolization of intracranial aneurysms.

\section{MATERIALS AND METHODS \\ Ethics Statement}

Written informed consent was obtained from each patient for the publication of this article and any accompanying images. This study was approved by the Ethics Committee of Zhengzhou University. The procedures followed were in accordance with the Helsinki Declaration of 1975, as revised in 1983.

\section{Patient Selection}

From October 2017 to July 2018, one hundred seven patients who were treated with stent-assisted embolization and met the following eligibility criteria were recruited for this study: 1) use of simple intracranial aneurysm stent-assisted (Neuroform EZ, Stryker Neurovascular, Kalamazoo, Michigan; Low Profile Visualized Intraluminal Support [LVIS], MicroVention, Tustin, California; Enterprise, Codman \& Shurtleff, Raynham, Massachusetts; Solitarie AB, Covidien, Irvine, California) coil embolization; 2) no use of a liquid embolic agent (Onyx; Covidien) or other embolic material; 3 ) no indications for surgery or refusal to undergo surgery; and 4) no use of a flow diverter. Moreover, the exclusion criteria were as follows: 1) use of only coil- or balloon-assisted embolization; 2) use of embolic material other than metal coils, such as Onyx or Woven EndoBridge (WEB; Sequent Medical, Aliso Viejo, California); 3) use of surgical aneurysm clipping alone or in combination with embolization; 4) use of a flow diverter; and 5) refusal of study participation.
Table 1: Aneurysm measurements

\begin{tabular}{lc}
\hline & Mean (mm) \\
\hline Dome width & $5.6 \pm 3.7$ \\
Dome-to-neck ratio & $1.2 \pm 0.7$ \\
Proximal parent artery diameter & $3.6 \pm 1.6$ \\
Distal parent artery diameter & $3.4 \pm 1.5$ \\
\hline
\end{tabular}

Among the 107 patients in the present study, 63 were men and 44 were women, and the mean age was $52.7 \pm 12.4$ years. Moreover, 68 patients (62 patients with 1 aneurysm and 6 patients with 2 aneurysms) had no symptoms and were found to have aneurysms during a routine health checkup. The other 39 patients developed headaches, nausea, and vomiting. CT or CSF examination or both were used for the diagnosis of SAH. CTA and/or MRA showed 34 cases with single aneurysms and 5 cases with 2 aneurysms. The clinical severity of subarachnoid hemorrhage was assessed using the Hunt and Hess scale. Hunt and Hess grade 1 was detected in 9 cases, grade 2 was detected in 24 cases, grade 3 was detected in 4 cases, and grade 4 was detected in 2 cases.

\section{Aneurysms}

Of the 118 aneurysms, 87 were detected in the anterior circulation, including 5 in the internal carotid artery cavernous sinus segment, 8 in the internal carotid artery clinoid segment, 19 in the ocular artery segments, 28 in the posterior communicating segments, 3 in the anterior cerebral artery A1 segments, 17 in the anterior communicating segments, and 7 in the middle cerebral artery bifurcation. Moreover, 31 aneurysms were detected in the posterior circulation, including 17 vertebral artery aneurysms, 10 basal artery stem aneurysms, and 4 basal artery top aneurysms. The spatial relationship between the aneurysms and the parent artery and its branches was confirmed via DSA and its 3D reconstruction function (Table 1).

\section{Procedures, DynaCT Micro Scan, and Image Reconstruction}

The procedures for perioperative management and stent-assisted embolization were similar to those described in previous reports. ${ }^{1-3,5,6}$ Immediately after stent-assisted embolization, 
conventional DynaCT was performed to rule out intraprocedural bleeding, and DynaCT Micro was performed to confirm stent deployment and apposition. The high-resolution DynaCT parameters were as follows: 20-second DynaCT Micro (x-ray voltage: $109 \mathrm{kV}$; electric current: $460 \mathrm{~mA}$ ); FOV, $22 \mathrm{~cm}$; maximum rotation range, $200^{\circ}$; rotation time, 20 seconds; and number of frames, 496. After completing data collection, the image data were automatically transferred to syngo X Workplace (4D, Siemens), and $3 \mathrm{D}$ reconstruction with or without SMART was performed respectively.

\section{Evaluating Image Quality of DynaCT and DynaCT Micro Combined with SMART}

The image was independently evaluated by 2 experienced neurointerventionists (J.M., with 12 years of experience; T.-F.L., with 10 years of experience). The evaluation criteria were as followsa platinum mark or double helical strands: invisible or fuzzy (0 points) or clear (1 point); nickel-titanium wire: invisible or fuzzy (0 points) or clear (1 point); coil metal artifacts: extensive or moderate ( 0 points) or mild or no artifacts ( 1 point); and nickel-titanium wire artifacts: extensive or moderate ( 0 points) or mild or no artifacts (1 point).

\section{Postoperative Evaluation and Follow-Up}

The degree of aneurysmal occlusion was evaluated using DSA immediately after the procedure and at the 3-month follow-up. Angiographic examinations were performed by 2 senior professional physicians (J.M., with 12 years of experience; X.-W.H., with 35 years of experience), and the findings were subsequently scored using the modified Raymond-Roy occlusion classification (MRRC) system. ${ }^{7}$ Complete occlusion was defined as the absence of contrast agent within the aneurysm intracavity; neck remnant was defined as the presence of contrast agent in the aneurysm neck; and aneurysm remnant was defined as the presence of contrast agent in a part of the aneurysm. Clinical outcomes were assessed at discharge and at 6 months using the mRS. Any death within 30 days after endovascular treatment was designated as a treatment-related death.

\section{Statistical Analysis}

All statistical analyses were performed using SPSS software, Version 19.0 (IBM, Armonk, New York). The measurement data are presented as mean \pm SD. Moreover, the $\chi^{2}$ or Fisher exact test was used for image-quality evaluation, and $P<.05$ was used to indicate statistical significance. The consistency between the 2 doctors in measuring the values of each indicator was tested using the $\kappa$ test, and $\kappa \geq 0.75$ was considered good.

\section{RESULTS}

\section{Technical and Anatomic Postoperative Results}

A total of 118 intracranial stents were successfully used for the embolization of 118 aneurysms. The choice of stent type and size primarily depended on aneurysm morphology, as well as the diameter and morphology of the parent artery. Among the stents used, 35 were Neuroform EZ stents, including four $2.5 \times 15 \mathrm{~mm}$ stents, four $2.5 \times$ $20 \mathrm{~mm}$ stents, four $3.0 \times 15 \mathrm{~mm}$ stents, six $3.0 \times 20 \mathrm{~mm}$ stents, one $3.5 \times 20 \mathrm{~mm}$ stent, three $3.5 \times 30 \mathrm{~mm}$ stents, eight $4.0 \times 20 \mathrm{~mm}$ stents, and five $4.5 \times 20 \mathrm{~mm}$ stents; 72 were LVIS stents, including sixteen $3.5 \times 15 \mathrm{~mm}$ stents, thirty $3.5 \times 20 \mathrm{~mm}$ stents, six $4.5 \times$ $15 \mathrm{~mm}$ stents, ten $4.5 \times 20 \mathrm{~mm}$ stents, seven $4.5 \times 30 \mathrm{~mm}$ stents, and three $5.5 \times 25 \mathrm{~mm}$ stents; and 11 were Enterprise stents, including nine $4.5 \times 22 \mathrm{~mm}$ stents and two $4.5 \times 28 \mathrm{~mm}$ stents.

On the basis of the findings of the high-resolution DynaCT Micro scan in the stent area in combination with multiple 2D angiography at selected working angles, 6 stents (5 LVIS stents, 1 Enterprise stent) exhibited incomplete deployment. After microguidewire looping dilation and balloon dilation, the stent apposition improved. In 15 patients, the coil embolization in the aneurysm neck was not dense (9 with Neuroform EZ, 4 with LVIS, and 2 with Enterprise stents). After adjusting the microcatheter head position, embolization was continued until dense packing was observed. In 1 case, during the embolization of an unruptured aneurysm in the C4 section, the microcatheter head detached from the aneurysm cavity, and re-superselective catheterization was not successful due to the small size of the residual portion of the aneurysm and the inability of the guidewire to pass through the LVIS stent mesh. Immediately after surgery, MRRC embolization grading was performed, and 97 (82.2\%) were categorized as class I, seventeen (14.4\%) were categorized as class II, and $4(3.4 \%)$ were categorized as class III (Figs $2 A-C$ and $3 A-C$ ).

\section{Evaluating Image Quality of DynaCT Micro Combined with SMART}

There was good consistency in the evaluation results between the 2 physicians $(\kappa$ value $=0.85, P<.05)$. A comparison of normal DynaCT reconstruction and DynaCT Micro reconstruction indicated that DynaCT Micro combined with SMART more clearly displayed the stent nickel-titanium wire and more effectively reduced coil metal artifacts. Moreover, the image quality was significantly improved $(P<.05$; Tables $2-5$, Figs $2 D-F$ and $3 D-F)$.

\section{Follow-Up}

A total of 107 patients were followed up for $9.7 \pm 2.4$ months. Among these, 93 patients (101 aneurysms) were followed via DSA for 6-13 months. The MRRC results were as follows: 90 (89.1\%) aneurysms as class I, nine (8.9\%) aneurysms as class II, and II (2.0\%) aneurysms as class III. In 3 cases with MRRC class I ( 2 cases with a Neuroform EZ and 1 case with an Enterprise stent), the coils were compressed, and the necks of aneurysms recurred (MRRC class II). Two of these cases underwent repeat embolization, and the other case underwent close observation. The mRS score during follow-up was 0 in 97 cases, 1 in 4 cases, 2 in 3 cases, 3 in 2 cases, and 4 in 1 case.

\section{Perioperative Complications}

A total of 5 patients had intraoperative complications, including various degrees of cerebral vasospasm (follow-up mRS score: 0 in 3 cases and 1 in 2 cases). No cases of intraoperative aneurysm rupture or stent thrombosis were noted. During the follow-up period, 2 patients developed subacute hydrocephalus (mRS scores of 2 and 3, respectively) and 2 patients developed a new cerebral infarction (caused by nonaneurysmal artery stenosis). None of these new conditions were related to the treatment of aneurysms. 


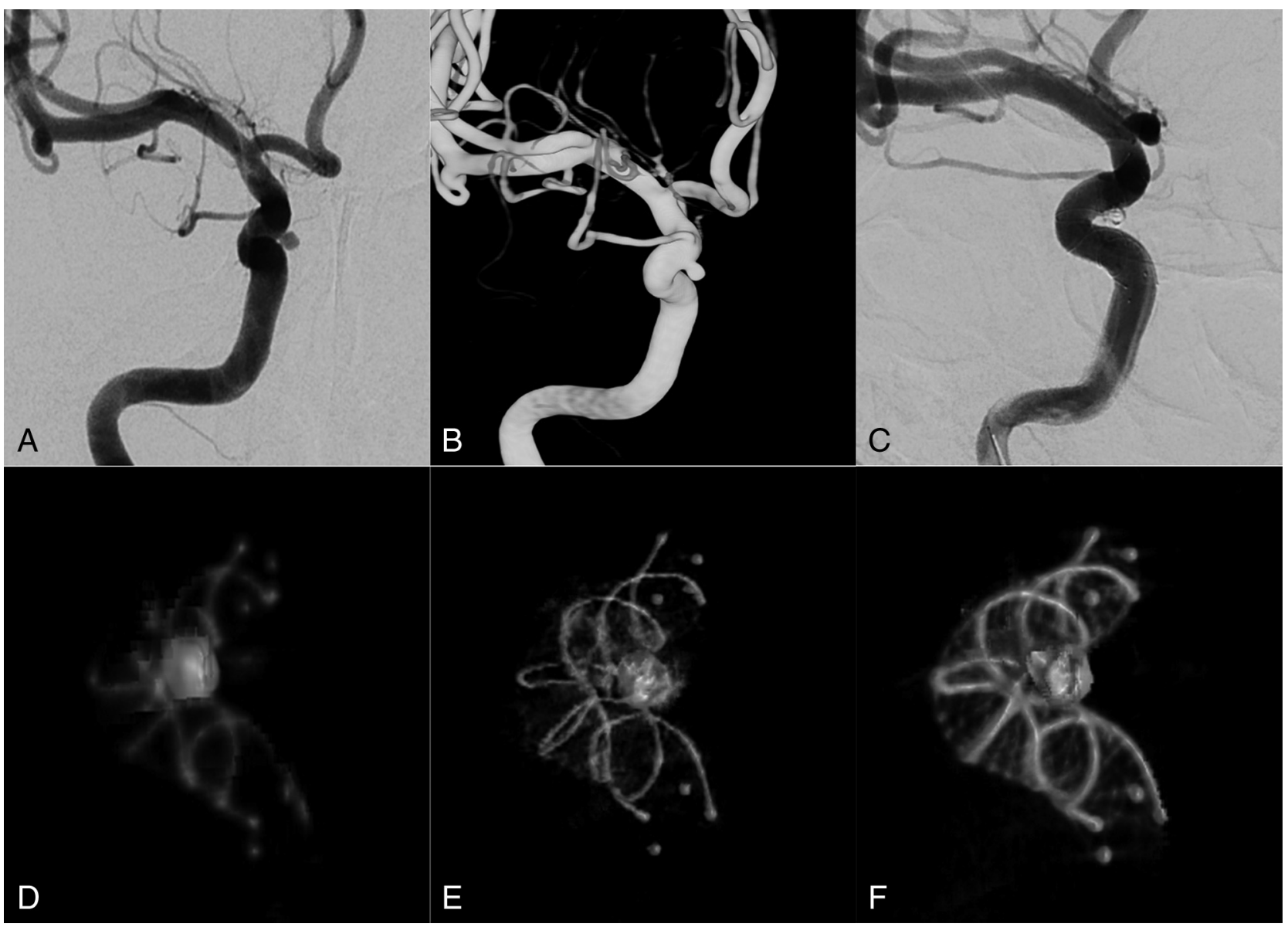

FIG 2. LVIS stent-assisted embolization of an unruptured aneurysm in the right ocular artery segments. $A$ and $B$, DSA and $3 D$ images show a wide-neck aneurysm in the right ocular artery segments $(1.6 \times 2.1 \mathrm{~mm})$. C, LVIS stent-assisted complete embolization $(4.5 \times 20 \mathrm{~mm})$ of an aneurysm classified as Raymond embolism class I. D, Normal DynaCT reconstructed images immediately after intervention show that the double helical marker wires of the stent are well developed, the nickel-titanium wires are poorly developed, and the coil metal artifacts are large. E, Immediate postoperative DynaCT Micro reconstructed images show that the double helical marker of the stent is well developed, but the nickel-titanium wire is still poorly developed. However, the appearance of metal wire and coil metal artifacts is significantly improved relative to normal DynaCT. F, Immediately after the operation, DynaCT Micro combined with SMART-reconstructed images shows that the double helix marker wires and nickel-titanium wire are well developed, the metal artifacts of the nickel-titanium wire and coils are significantly reduced, and the overall image quality is significantly improved.

\section{DISCUSSION}

Endovascular embolization has become an important method for the treatment of intracranial aneurysms. The International Subarachnoid Aneurysm Trial (ISAT) has confirmed the safety and effectiveness of endovascular embolization for the treatment of intracranial aneurysms. ${ }^{8}$ However, the use of coil embolization alone for intracranial wide-neck aneurysms (aneurysm neck $>4 \mathrm{~mm}$ or aneurysm neck/aneurysm body $>1: 2$ ) remains technically challenging. The use of stents could not only assist the embolization but also promote the healing of the aneurysm neck. However, the diameter of the nickel-titanium wire in the currently available aneurysm stents is close to the detection limit of radiographs (including 0.0024 inches for the LVIS stent and 0.01 inches for the Neuroform EZ stent). Although platinum marks or double helixes may be observed in some cases during intervention, local distortion or incomplete stent expansion may be difficult to determine in other cases. Moreover, some aneurysms with a serious neck embolism may be overlooked due to a limited angiographic angle or the presence of coil metal artifacts. ${ }^{9,10}$ This is an important potential risk factor for stent thrombosis, penetrating vascular occlusion, and prolonged stent re-endothelialization time. ${ }^{11}$ Moreover, due to the impact of metal artifacts of the coil and the stent wire, conventional C-arm CT devices, such as DynaCT, VasoCT (Philips Healthcare, Best, the Netherlands), or Innova CT (GE Healthcare, Milwaukee, Wisconsin), may not be able to fully clarify the relationship between the stent and the aneurysm neck, as well as the relationship between the stent and the embolized coils. This issue may lead to the misjudgment of the degree of packing density of the aneurysm neck by the surgeon and could lead to postoperative aneurysm recurrence. ${ }^{4,12}$

Compared with conventional C-arm CT, the high-resolution C-arm CT (DynaCT Micro) used the nonbinning technique rather than the regular $2 \times 2$ pixel binning, adapted the acquisition parameters to include only a small FOV for small object visualization, and optimized the exposure parameters and imageprocessing algorithm to obtain enhanced image quality. The DynaCT Micro enabled the visualization of local lesions/devices 


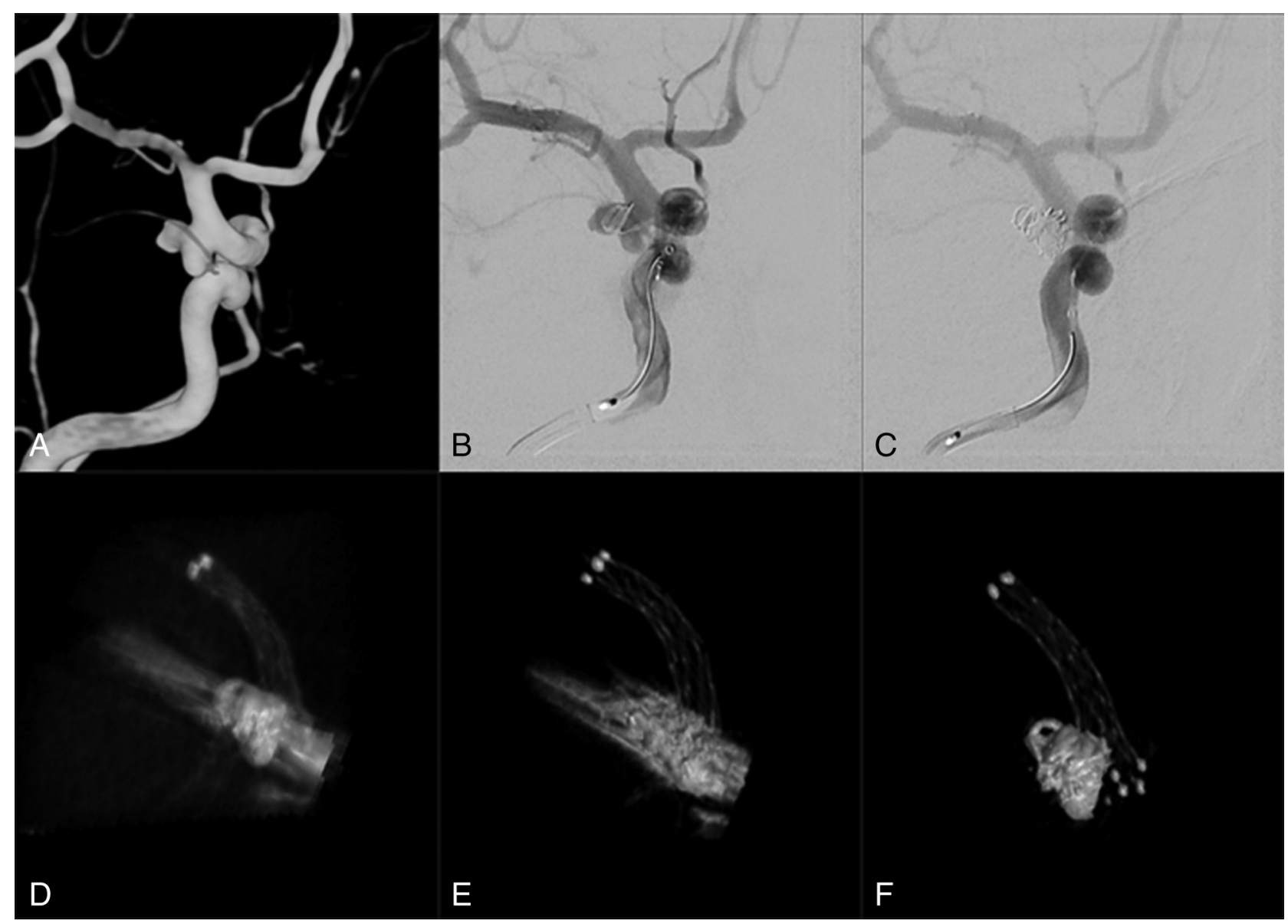

FIG 3. Neuroform EZ stent-assisted embolization of a ruptured aneurysm in the right posterior communicating artery. $A$ and $B$, DSA and $3 D$ reconstructed images show a right posterior communicating wide-neck aneurysm with an irregular petal shape (tumor neck: $3.4 \mathrm{~mm} ; 2$ daughter sacs of $2.8 \times 3.6$ and $2.4 \times 3.1 \mathrm{~mm})$. C, Complete aneurysm embolization with the Neuroform EZ stent $(3.5 \times 30 \mathrm{~mm})$ while maintaining artery patency. $D$, Normal DynaCT reconstructed images immediately after the operation show that the stent mark is clearly developed, the stent wire is poorly developed, and the coil metal artifacts are large. E, DynaCT Micro reconstructed images immediately after the operation show that the mark at the 2 ends of the stent is well developed, the stent wire is significantly well developed (relative to normal DynaCT), and the coil metal artifacts are still large; $F$, Reconstructed images of DynaCT Micro combined with SMART immediately after the operation show that the marks of the stent and the nickel-titanium wire are well developed, the metal artifacts of the stent wire and coils are significantly reduced, and the overall image quality is significantly improved.

Table 2: Evaluation of images obtained with DynaCT, DynaCT Micro, and DynaCT Micro combined with SMART (Neuroform EZ stent, $n=35$ )

\begin{tabular}{|c|c|c|c|c|c|c|c|c|}
\hline \multirow[b]{2}{*}{ Methods } & \multicolumn{2}{|c|}{$\begin{array}{l}\text { Platinum } \\
\text { Marks }\end{array}$} & \multicolumn{2}{|c|}{$\begin{array}{c}\text { Nickel-Titanium } \\
\text { Wire } \\
\end{array}$} & \multicolumn{2}{|c|}{$\begin{array}{c}\text { Coil Metal } \\
\text { Artifacts }\end{array}$} & \multicolumn{2}{|c|}{$\begin{array}{l}\text { Nickel-Titanium } \\
\text { Wire Artifacts }\end{array}$} \\
\hline & 0 & $\overline{1}$ & 0 & 1 & 0 & 1 & 0 & 1 \\
\hline DynaCT & 0 & 35 & 35 & 0 & 35 & 0 & 35 & 0 \\
\hline DynaCT Micro & 0 & 35 & 32 & 3 & 27 & 8 & 28 & 7 \\
\hline DynaCT Micro combined with SMART & 0 & 35 & 8 & 27 & 7 & 28 & 6 & 29 \\
\hline
\end{tabular}

with enhanced spatial resolution, with and without the use of diluted contrast agents. MAR techniques are widely used in spiral $\mathrm{CT}$ and MR imaging to reduce artifacts generated by metal implants and improve the overall image quality. However, their application in C-arm CT is still in its infancy, and only a few reports are found in the literature. Van der Bom et al ${ }^{12}$ reported 25 cases of stent-assisted coil embolization using high-resolution VasoCT combined with MAR. They found that although the technology significantly improved the image quality, it still could not eliminate the metal artifacts produced by the embolism coils. In the aforementioned study, the MAR algorithm was based on the method proposed by Prell et al. ${ }^{13}$ Thus, the matrix dimension $\left(512^{3}\right.$ versus $\left.256^{3}\right)$ obtained in volume reconstruction was significantly improved, and higher image resolution ${ }^{4}$ was obtained. Innovations and combinations of SMART and high-resolution C-arm CT have theoretically contributed to the improvement of local image quality; however, at present, only a few reports have cited the clinical applications of high-resolution C-arm CT 
Table 3: Evaluation of images obtained with DynaCT, DynaCT Micro, and DynaCT Micro combined with SMART (LVIS stent, $n=72$ )

\begin{tabular}{|c|c|c|c|c|c|c|c|c|}
\hline \multirow[b]{2}{*}{ Methods } & \multicolumn{2}{|c|}{$\begin{array}{l}\text { Double Helix } \\
\text { Marker Wires }\end{array}$} & \multicolumn{2}{|c|}{$\begin{array}{c}\text { Nickel-Titanium } \\
\text { Wire }\end{array}$} & \multicolumn{2}{|c|}{$\begin{array}{l}\text { Coil Metal } \\
\text { Artifacts }\end{array}$} & \multicolumn{2}{|c|}{$\begin{array}{l}\text { Nickel-Titanium } \\
\text { Wire Artifacts }\end{array}$} \\
\hline & 0 & $\overline{1}$ & 0 & 1 & $\overline{0}$ & 1 & 0 & 1 \\
\hline DynaCT & 0 & 72 & 72 & 0 & 72 & 0 & 72 & 0 \\
\hline DynaCT Micro & 0 & 72 & 66 & 6 & 65 & 7 & 65 & 7 \\
\hline DynaCT Micro combined with SMART & 0 & 72 & 21 & 51 & 26 & 46 & 29 & 43 \\
\hline
\end{tabular}

Table 4: Evaluation of images obtained with DynaCT, DynaCT Micro, and DynaCT Micro combined with SMART (Enterprise stent, $n=11$ )

\begin{tabular}{|c|c|c|c|c|c|c|c|c|}
\hline \multirow[b]{2}{*}{ Methods } & \multicolumn{2}{|c|}{$\begin{array}{l}\text { Platinum } \\
\text { Marks }\end{array}$} & \multicolumn{2}{|c|}{$\begin{array}{c}\text { Nickel- } \\
\text { Titanium Wire } \\
\end{array}$} & \multicolumn{2}{|c|}{$\begin{array}{l}\text { Coil Metal } \\
\text { Artifacts } \\
\end{array}$} & \multicolumn{2}{|c|}{$\begin{array}{l}\text { Nickel-Titanium } \\
\text { Wire Artifacts }\end{array}$} \\
\hline & $\overline{0}$ & $\overline{1}$ & 0 & $\overline{1}$ & 0 & 1 & 0 & 1 \\
\hline DynaCT & 0 & 11 & 11 & 0 & 11 & 0 & 11 & 0 \\
\hline DynaCT Micro & 0 & 11 & 10 & 1 & 8 & 3 & 9 & 2 \\
\hline DynaCT Micro combined with SMART & 0 & 11 & 3 & 8 & 4 & 7 & 3 & 8 \\
\hline
\end{tabular}

Table 5: Comparison of the image quality in different groups ( $P$ values)

\begin{tabular}{|c|c|c|c|c|c|c|c|c|c|}
\hline \multirow[b]{2}{*}{ Comparison Groups } & \multicolumn{3}{|c|}{ Neuroform EZ Stent } & \multicolumn{3}{|c|}{ LVIS Stent } & \multicolumn{3}{|c|}{ Enterprise Stent } \\
\hline & $\begin{array}{c}\text { Nickel- } \\
\text { Titanium } \\
\text { Wire }\end{array}$ & $\begin{array}{c}\text { Coil } \\
\text { Metal } \\
\text { Artifacts }\end{array}$ & $\begin{array}{l}\text { Nickel- } \\
\text { Titanium } \\
\text { Wire } \\
\text { Artifacts }\end{array}$ & $\begin{array}{l}\text { Nickel- } \\
\text { Titanium } \\
\text { Wire }\end{array}$ & $\begin{array}{c}\text { Coil } \\
\text { Metal } \\
\text { Artifacts }\end{array}$ & $\begin{array}{l}\text { Nickel- } \\
\text { Titanium } \\
\text { Wire } \\
\text { Artifacts }\end{array}$ & $\begin{array}{l}\text { Nickel- } \\
\text { Titanium } \\
\text { Wire }\end{array}$ & $\begin{array}{c}\text { Coil } \\
\text { Metal } \\
\text { Artifacts }\end{array}$ & $\begin{array}{l}\text { Nickel- } \\
\text { Titanium } \\
\text { Wire } \\
\text { Artifacts }\end{array}$ \\
\hline $\begin{array}{l}\text { DynaCT vs DynaCT } \\
\text { Micro }\end{array}$ & .239 & .050 & .050 & .028 & .013 & .013 & 1 & .214 & .476 \\
\hline $\begin{array}{l}\text { DynaCT vs DynaCT } \\
\text { Micro combined } \\
\text { with SMART }\end{array}$ & $<.001$ & $<.001$ & $<.001$ & $<.001$ & $<.001$ & $<.001$ & .001 & $<.004$ & .001 \\
\hline $\begin{array}{l}\text { DynaCT Micro vs } \\
\text { DynaCT Micro } \\
\text { combined with } \\
\text { SMART }\end{array}$ & $<.001$ & $<.001$ & $<.001$ & $<.001$ & $<.001$ & $<.001$ & .008 & .199 & .030 \\
\hline
\end{tabular}

combined with MARs. ${ }^{4,12}$ In the present study, we observed 3 different types of stents (Neuroform EZ, LVIS, and Enterprise) using 3 different C-arm CT techniques-ie, conventional C-arm CT, high-resolution C-arm CT, and high-resolution C-arm CT with SMART. High-resolution C-arm CT combined with SMART had the highest image quality among all 3 imaging methods.

Unlike previously reported studies that used high-resolution Carm CT with diluted contrast agents, our study focused on high-resolution C-arm CT without the use of any contrast agent. For stentassisted coiling, the observation of stent deployment, packing density at the aneurysm neck, and the coil-stent relationship is more crucial to the surgeon than stent/vessel wall apposition. Nonenhanced highresolution $\mathrm{C}$-arm $\mathrm{CT}$ is a more convenient and quicker method for surgeons to confirm stent/coil deployment, without the need for a high-pressure injection or other complex procedures for diluting the contrast agent. For our future studies on flow-diverter visualization, enhanced C-arm CT will be used for the direct evaluation of the flow diverter/vessel wall relationship.

In the present study, based on the results of reconstruction with high-resolution DynaCT combined with SMART and multiple 2D angiography at selected working angles, we confirmed that 6 stents had mild incomplete expansion and that the wall condition had improved after microguidewire looping dilation and balloon dilation. On the basis the results of DynaCT Micro combined with $2 \mathrm{D}$ angiography at working angles, we found that the embolization of the aneurysm neck in 15 patients was unsatisfactory; therefore, we adjusted the microcatheter head to continue coil embolization and achieve the required density in the aneurysm neck. In these patients, due to the influence of vascular angles as well as coil and stent metal artifacts, it was difficult for conventional DynaCT and angiography to directly determine whether the coils in the aneurysm neck were dense, whether the coils protruded out of the aneurysm cavity or protruded into the stent, and whether the stent was completely expanded at the neck of the aneurysm. Caroff et $\mathrm{al}^{14}$ used VasoCT to observe the stent-assisted embolization of intracranial aneurysms and reported that the use of high-resolution flat panel CT could reduce the incidence of thromboembolic events. This finding was supported by the fact that no serious complications, such as acute thrombosis or ruptured aneurysm, were observed in the present study. However, the results of DSA immediately after the operation and during the followup period indicated a greater proportion of patients with a Raymond I classification than previously reported $(82.2 \%$ versus $36.4 \%-75.6 \%$; $89.1 \%$ versus $81.8 \%-88 \%) .{ }^{15-17}$

Although there are differences in the inclusion criteria among the studies as well as the technical proficiency of the surgeons involved at the different centers, we clearly found that DynaCT Micro combined with SMART reconstruction could help 
surgeons determine whether the stent has completely expanded and attached to the vascular wall and whether embolization of the aneurysm neck is satisfactory. Theoretically, this would improve the effect of stent-assisted aneurysm embolization and reduce the incidence of complications.

\section{CONCLUSIONS}

DynaCT Micro combined with SMART could improve the visualization of stent deployment and coil packing at the aneurysm neck in the stent-assisted embolization of intracranial aneurysms. This novel imaging technique could potentially reduce the incidence of postoperative complications and the recurrence of aneurysms. However, this is a single-center study, and the sample size is small; hence, our findings have certain limitations. A longterm study with a large sample size, as well as a multicenter, double-blind controlled study will be needed to confirm the reliability and long-term efficacy of this method.

\section{REFERENCES}

1. Santillan A, Boddu S, Schwarz J, et al. LVIS Jr. stent for treatment of intracranial aneurysms with parent vessel diameter of $2.5 \mathrm{~mm}$ or less. Interv Neuroradiol 2018;24:246-53 CrossRef Medline

2. Iosif C, Piotin M, Saleme S, et al. Safety and effectiveness of the Low Profile Visualized Intraluminal Support (LVIS and LVIS Jr) devices in the endovascular treatment of intracranial aneurysms: results of the TRAIL multicenter observational study. J NeuroIntervent Surg 2018;10:675-81 CrossRef Medline

3. Li TF, Shui SF, Han XW, et al. The use of Solitaire AB stents in coil embolization of wide-necked cerebral aneurysms. PLoS One 2015;10:e0139714 CrossRef Medline

4. Yuki I, Kambayashi Y, Ikemura A, et al. High-resolution C-arm CT and metal artifact reduction software: a novel imaging modality for analyzing aneurysms treated with stent-assisted coil embolization. AJNR Am J Neuroradiol 2016;37:317-23 CrossRef Medline

5. Ulfert C, Pham M, Sonnberger M, et al. The Neuroform Atlas stent to assist coil embolization of intracranial aneurysms: a multicenter experience. J NeuroIntervent Surg 2018;10:1192-96 CrossRef Medline

6. Ge H, Lv X, Yang X, et al. LVIS Stent versus Enterprise stent for the treatment of unruptured intracranial aneurysms. World Neurosurg 2016;91:365-70 CrossRef Medline
7. Roy D, Milot G, Raymond J. Endovascular treatment of unruptured aneurysms. J Stroke 2001;32:1998-2004 CrossRef Medline

8. Molyneux A, Kerr R, International Subarachnoid Aneurysm Trial (ISAT) Collaborative Group, et al. International Subarachnoid Aneurysm Trial (ISAT) of neurosurgical clipping versus endovascular coiling in 2143 patients with ruptured intracranial aneurysms: a randomized trial. J Stroke Cerebrovasc Dis 2002; 11:304-14 CrossRef Medline

9. Struffert T, Lang S, Adamek E, et al. Angiographic C-arm CT visualization of the Woven EndoBridge cerebral aneurysm embolization device (WEB): first experience in an animal aneurysm model. Clin Neuroradiol 2014;24:43-49 CrossRef Medline

10. Pfaff J, Struffert T, Gölitz P, et al. Angiographic CT for intraprocedural monitoring of complex neuroendovascular procedures. AJNR Am J Neuroradiol 2013;34:E77-80 CrossRef Medline

11. Foin N, Gutiérrez-Chico JL, Nakatani S, et al. Incomplete stent apposition causes high shear flow disturbances and delay in neointimal coverage as a function of strut to wall detachment distance: implications for the management of incomplete stent apposition. Circ Cardiovasc Interv 2014;7:180-89 CrossRef Medline

12. van der Bom IM, Hou SY, Puri AS, et al. Reduction of coil mass artifacts in high-resolution flat detector conebeam CT of cerebral stent-assisted coiling. AJNR Am J Neuroradiol 2013;34:2163-70 CrossRef Medline

13. Prell D, Kalender WA, Kyriakou Y. Development, implementation and evaluation of a dedicated metal artefact reduction method for interventional flat-detector CT. Br J Radiol 2010;83:1052-62 CrossRef Medline

14. Caroff J, Mihalea C, Neki H, et al. Role of C-arm VasoCT in the use of endovascular WEB flow disruption in intracranial aneurysm treatment. AJNR Am J Neuroradiol 2014;35:1353-57 CrossRef Medline

15. Wang CC, Li W, Feng ZZ, et al. Preliminary experience with stent-assisted coiling of aneurysms arising from small $(<2.5$ mm) cerebral vessels using the Low-Profile Visualized Intraluminal Support Device. AJNR Am J Neuroradiol 2017; 38:1163-68 CrossRef Medline

16. Wang CC, Fang YB, Zhang P, et al. Reconstructive endovascular treatment of vertebral artery dissecting aneurysms with the LowProfile Visualized Intraluminal Support (LVIS) device. PLoS One 2017;12:e0180079 CrossRef Medline

17. Qin F, Li Z, Fang X, et al. Therapeutic effect of Enterprise stentassisted embolization for very small ruptured intracranial aneurysms. Medicine (Baltimore) 2017;96:e7832 CrossRef Medline 